\title{
Infrared detector activities at NASA Langley Research Center
}

\author{
M.N. Abedin ${ }^{1}$, T.F. Refaat ${ }^{2}$, O.V. Sulima ${ }^{3}$, and F. Amzajerdian ${ }^{1}$ \\ ${ }^{1}$ NASA Langley Research Center, Hampton, VA 23681 \\ ${ }^{2}$ Old Dominion University, Norfolk, VA 23529 \\ ${ }^{3}$ University of Delaware, Newark, DE 19716
}

\begin{abstract}
Infrared detector development and characterization at NASA Langley Research Center will be reviewed. These detectors were intended for ground, airborne, and space borne remote sensing applications. Discussion will be focused on recently developed single-element infrared detector and future development of near-infrared focal plane arrays (FPA). The FPA will be applied to next generation space-based instruments. These activities are based on phototransistor and avalanche photodiode technologies, which offer high internal gain and relatively low noise-equivalent-power. These novel devices will improve the sensitivity of active remote sensing instruments while eliminating the need for a high power laser transmitter.
\end{abstract}

\section{INTRODUCTION}

NASA's Earth Science Technology Office and Science Mission Directorate show great interest in broadband detectors for numerous critical applications such as temperature sensing, process control, and atmospheric monitoring of trace gases $\left(\mathrm{CO}_{2}\right.$, $\mathrm{H}_{2} \mathrm{O}, \mathrm{CO}$, and $\mathrm{CH}_{4}$ ). When selecting a detector for such applications, key parameters, must be considered in order to satisfy the requirements of the Earth and planetary remote sensing systems. These parameters include spectral response, quantum efficiency, noiseequivalent-power (NEP), and gain. In general, large format focal plane arrays (FPA) in the 1.0- to $2.5-\mu \mathrm{m}$ spectral range are the detectors of choice for the next-generation Earth and Space Science remote sensing, Mars Orbiter, and planetary instruments. An Antimonide ( $\mathrm{Sb}$ )-based heterojunction phototransistor (HPT), as a suitable candidate, stimulates a strong interest for broadband remote sensing applications [1-4]. Besides p-i-n photodiodes and avalanche photodiodes (APD), HPTs have also attracted a great attention to satisfy many of the detector requirements for these applications without excess noise and high bias voltage problems, while maintaining superior NEP. HPT has an internal gain mechanism that allows increasing the output signal and signal-to-noise ratio (SNR). However, further reduction of gain related noise is desirable, and research on different HPT structures indicates some important design considerations that can minimize device noise and further increase the SNR.

On the other hand, APDs are integrated solid-state semiconductor devices that manufactured using different materials. The common near-IR InGaAs/InP APDs are operational in the spectral range of 0.9 to $1.6 \mu \mathrm{m}$ [5-7]. Recently, a group from DRS Technologies demonstrated responsivity of $\sim 15 \mathrm{~A} / \mathrm{W}$ using $\mathrm{HgCdTe}$ electron (e-) APD at 
short wave infrared (SWIR) wavelength (at $-7 \mathrm{~V}$ and $20^{\circ} \mathrm{C}$ ) [7]. However, $\mathrm{HgCdTe}$ eAPDs have demonstrated very high responsivity in the 3- to 5- $\mu \mathrm{m}$ range and their SWIR responsivity was low [7]. Even though $\mathrm{HgCdTe}$ detectors are efficient in the infrared range, significant technology limitations curb their application in that range. Therefore, researchers have been looking to other III-V systems that provide much higher yield by manufacturing and higher operability. In this context, it is necessary to explore alternative material systems, which can absorb radiation in the 1.0 - to 2.5 - $\mu \mathrm{m}$ range and are compatible with general requirements of a low-noise detector. InGaAsSb/AlGaAsSb heterostructures are very suitable for this application, and single-element HPTs based on these heterostructures demonstrated record responsivitites [3, 4, 8-14].

Quaternary InGaAsSb/AlGaAsSb HPTs in the 1.0- to 2.5- $\mu \mathrm{m}$ wavelength range have been developed and fabricated at AstroPower, Inc. in collaboration with NASA Langley Research Center (LaRC). These devices have been characterized at NASA LaRC and encouraging results have been obtained, including high responsivity, high detectivity, and relatively low NEP [3,4, 8-14]. Development of large-format Sb-based phototransistor FPA will enhance the capability of space-based active and passive remote sensing imaging systems and enable major advances in Astronomical, Earth, and planetary instruments. This new detector will enhance the capability of active remote sensing of $\mathrm{CO}_{2}$ and water vapor at 2.05 and $1.9 \mu \mathrm{m}$, respectively.

There is no commercially available broadband detector with sufficient sensitivity in the 1.0- to $2.5-\mu \mathrm{m}$ spectral range, whereas this spectral range is suitable for sounding Earth and planetary atmospheres. Therefore, we propose to develop the capability to reliably fabricate detector arrays that respond to broad near-IR wavelength regions.

\section{DEMONSTRATION OF SINGLE ELEMENT INFRARED DETECTOR}

Recently, NASA LaRC characterized single-element InGaAsSb/AlGaAsSb HPTs with a $200 \mu \mathrm{m}$ diameter. Figure 1 shows the responsivity variation with wavelength in the $0.6-$ to $2.4-\mu \mathrm{m}$ range at different collector-emitter voltages and temperatures of such a device [11]. The responsivity is strongly dependent on wavelength, temperature, and bias voltage. A maximum responsivity of $10000 \mathrm{~A} / \mathrm{W}$ was achieved at $1.9-\mu \mathrm{m},-193^{\circ} \mathrm{C}$ and $5 \mathrm{~V}$. That was the highest responsivity ever reported in the 0.6 - to $2.4-\mu \mathrm{m}$ wavelength range for the Sb-based photodetectors.

Figure 2 compares the NEP variation with bias voltage of a HPT and of commercial InGaAs p-i-n photodiodes (Hamamatsu; G5852 and G5853) at different wavelengths [10]. The photodiodes have different cutoff wavelengths: $2.6-\mu \mathrm{m}$ for G5853 and $2.3-\mu \mathrm{m}$ for G5852. It was determined that at $2 \mu \mathrm{m}$, NEP of G5852 (top solid lines at $-20{ }^{\circ} \mathrm{C}$ ) is about five times lower compared to G5853. Comparison with the best of the tested p-i-n photodiodes shows that at $4.0 \mathrm{~V}$ the HPT achieves near an order of magnitude lower NEP despite the 40 degrees higher operating temperature $\left(20^{\circ} \mathrm{C}\right)$. Furthermore, this HPT was also operated at $-20^{\circ} \mathrm{C}$ and NEP was reduced to $1.83 \times 10^{-14} \mathrm{~W} / \mathrm{Hz}^{1 / 2}$ at the same operating conditions. 


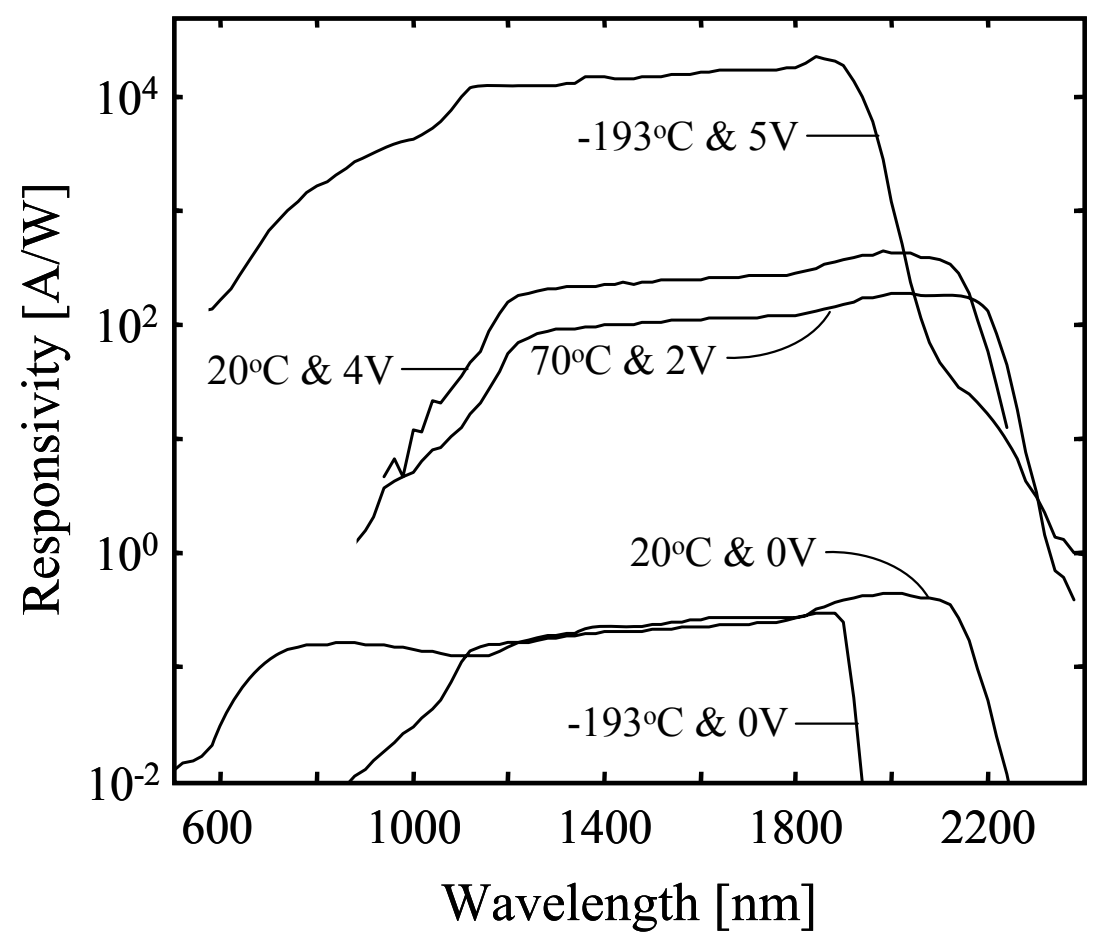

Fig 1 . Responsivity variation with wavelength at different bias voltages and temperatures for an HPT sample (A1-d2) [11].

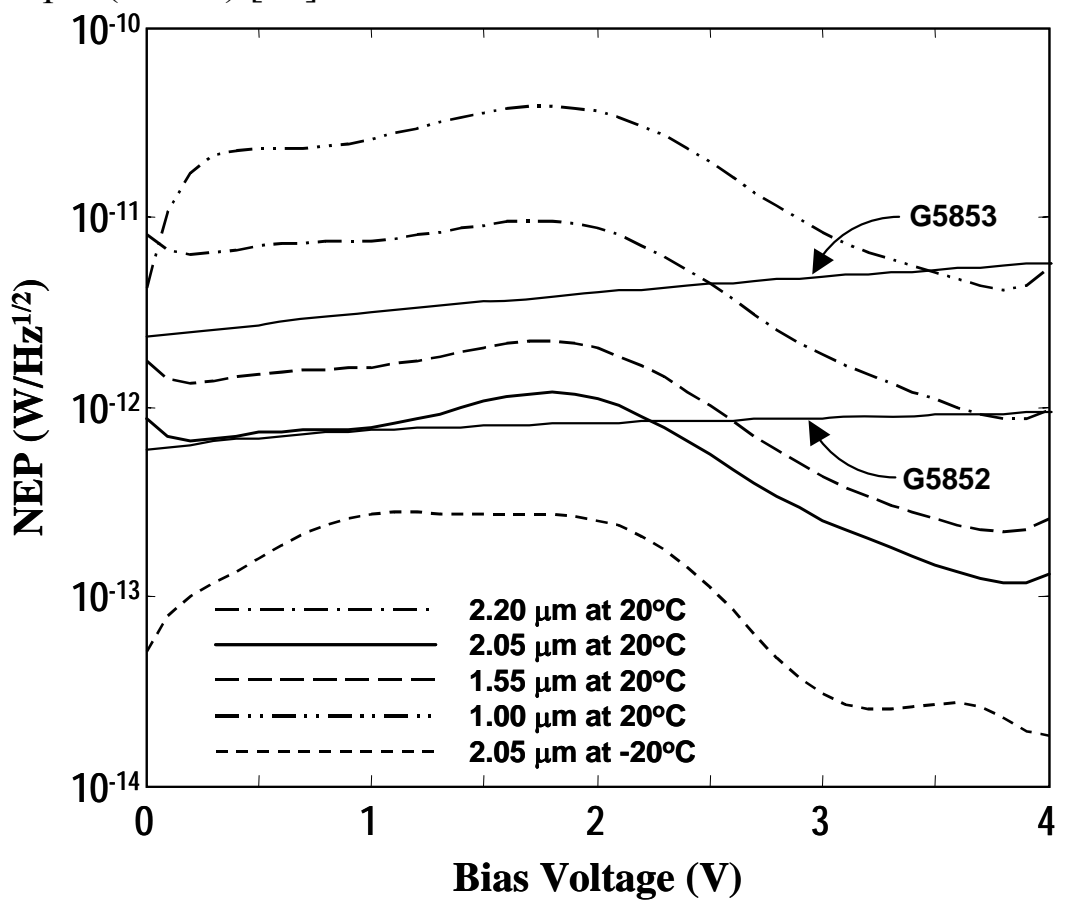

Fig 2. Comparison of the NEP variation with bias voltage between HPT and commercial p-i-n photodiodes [10]. The NEP of the p-i-n photodiodes were measured at $2 \mu \mathrm{m}, 1.0 \mathrm{~V}$ and $-20^{\circ} \mathrm{C}$. 
In addition, commercial APDs were acquired and characterized at NASA LaRC. Spectral response measurements of InGaAs APDs from Perkin-Elmer (APD1 with $80 \mu \mathrm{m}$ diameter) and Sensors Unlimited Inc./Goodrich (APD2 with $200 \mu \mathrm{m}$ ) were performed. Figure 3 shows responsivity curves as a function of wavelength of the InGaAs APDs and phototransistor. The selected biases for the APDs were $52.0 \mathrm{~V}$ and $53.4 \mathrm{~V}$ at $20^{\circ} \mathrm{C}$ as specified by the manufacturers and the bias voltage for HPT was $4.0 \mathrm{~V}$ at $-20^{\circ} \mathrm{C}$. These two APDs have similar cutoff wavelengths near $1.7-\mu \mathrm{m}$, but the HPT has the cutoff at approximately $2.1-\mu \mathrm{m}$. The following responsivities were determined: above $100 \mathrm{~A} / \mathrm{W}$ $\left(20^{\circ} \mathrm{C}\right.$ and $\left.53.4 \mathrm{~V}\right)$ for APD2 and about $85 \mathrm{~A} / \mathrm{W}\left(20^{\circ} \mathrm{C}\right.$ and $\left.52.0 \mathrm{~V}\right)$ for APD1 at $1.6-\mu \mathrm{m}$ wavelength; and about $260 \mathrm{~A} / \mathrm{W}\left(20^{\circ} \mathrm{C}\right.$ and $\left.3.0 \mathrm{~V}\right)$ and $1700 \mathrm{~A} / \mathrm{W}\left(-20^{\circ} \mathrm{C}\right.$ and $\left.4.0 \mathrm{~V}\right)$ for phototransistor at $2.0-\mu \mathrm{m}$. These are the highest responsivities measured for those APDs and phototransistor at different breakdown and bias voltages at $20^{\circ} \mathrm{C}$ and $-20^{\circ} \mathrm{C}$, respectively.

Figure 4 shows the NEP characteristics of the InGaAs APDs and of the HPT at different wavelengths and at the same bias voltage and temperature settings used for the spectral response measurements. The following NEP is determined: about $6 \times 10^{-15}$ $\mathrm{W} / \mathrm{Hz}^{1 / 2}$ for APD1 $\left(20^{\circ} \mathrm{C}\right.$ and $\left.52.0 \mathrm{~V}\right)$ and about $7 \times 10^{-13} \mathrm{~W} / \mathrm{Hz}^{1 / 2}$ for APD2 at $1.6-\mu \mathrm{m}$ wavelength. For the HPT, the NEP is determined $\sim 1.2 \times 10-12 \mathrm{~W} / \mathrm{Hz}^{1 / 2}\left(20^{\circ} \mathrm{C}\right.$ and $\left.3.0 \mathrm{~V}\right)$ and $\sim 4.6 \times 10^{-14} \mathrm{~W} / \mathrm{Hz}^{1 / 2}\left(-20^{\circ} \mathrm{C}\right.$ and $\left.4.0 \mathrm{~V}\right)$ at $2.0-\mu \mathrm{m}$ wavelength. Comparison with the tested avalanche photodiodes measured at $20^{\circ} \mathrm{C}$ shows that at breakdown voltage, APD1 achieves near two order of magnitude lower NEP than APD2 and one order of magnitude lower NEP than phototransistor, when it was cooled down to $-20^{\circ} \mathrm{C}$. We believe that these discrepancies are due to the higher noise of APD2 and phototransistor as compared to APD1.

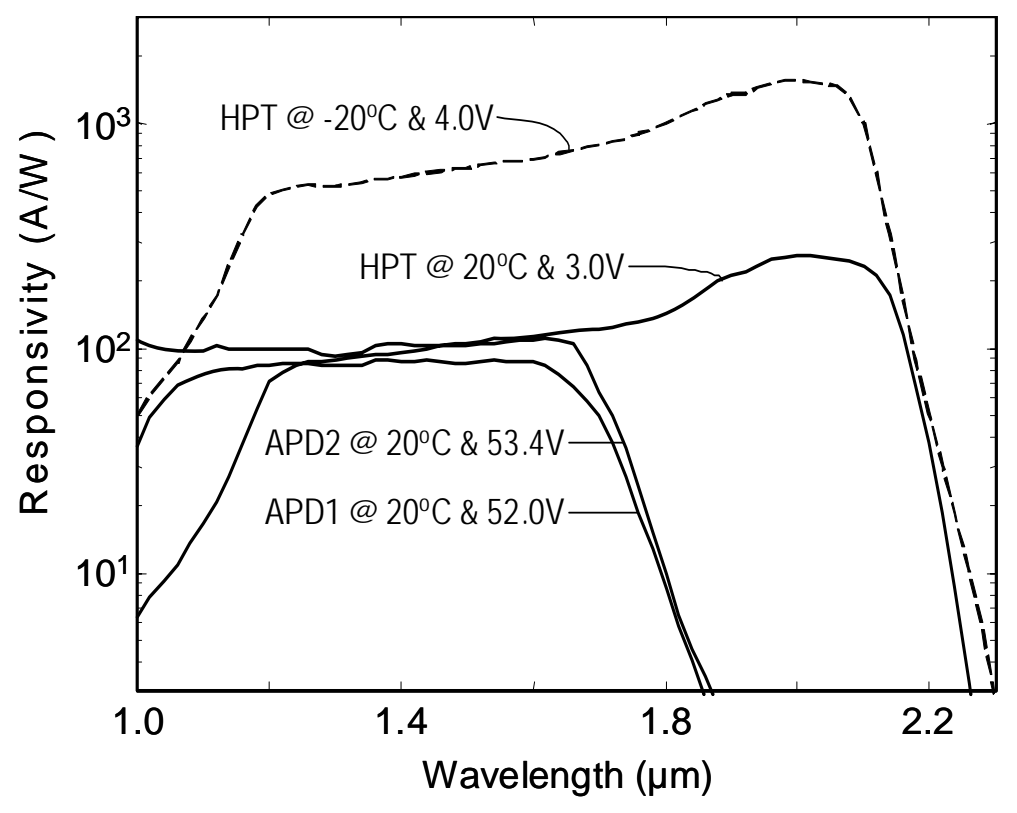

Fig 3. Spectral response variation of the APDs and the phototransistor with wavelength at different bias voltages and temperatures $\left(20^{\circ} \mathrm{C}\right.$ and $\left.-20^{\circ} \mathrm{C}\right)$. 


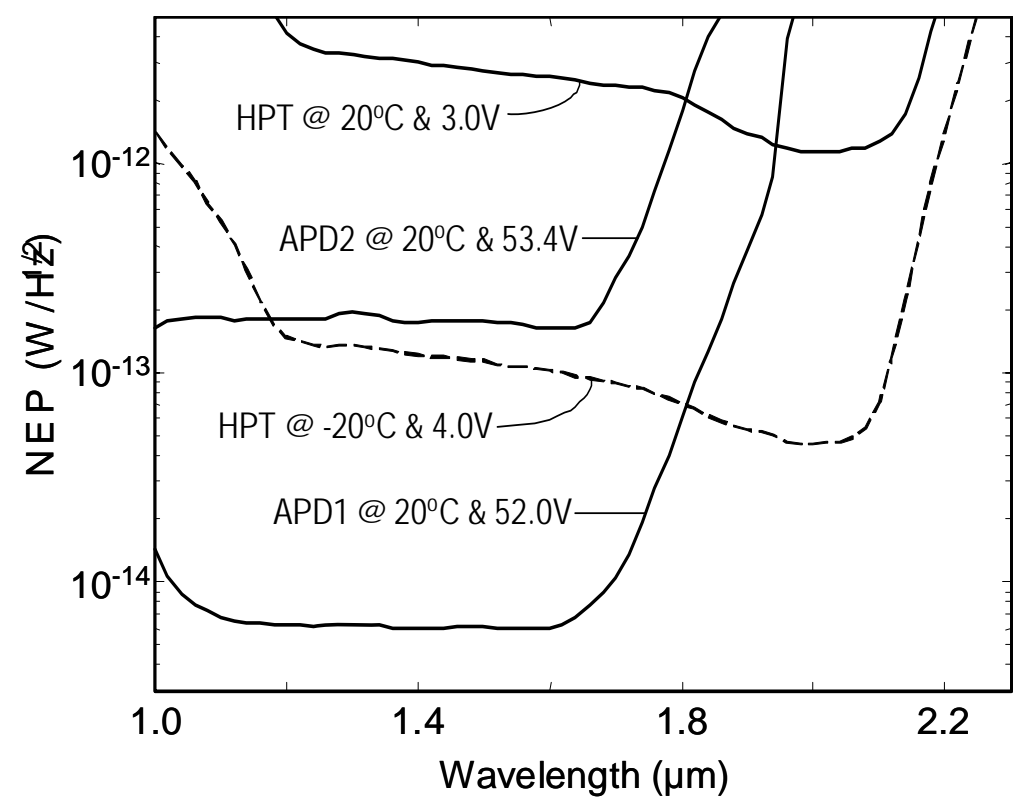

Fig 4. Comparison of NEP between the APDs and the phototransistor at the same operating conditions $\left(20^{\circ} \mathrm{C}\right.$ and $\left.-20^{\circ} \mathrm{C}\right)$.

The HPTs have longer wavelength sensitivity and a comparably short wavelength sensitivity, which is an attractive solution for the broadband imaging systems. The attraction to this solution is because the easiest way to acquire broadband imaging is to use a single detector array with simple optics and electronics. For commercial technologies (for example, Si-cutoff $1.1 \mu \mathrm{m}$ and InGaAs: 1.7 or extended $2.6 \mu \mathrm{m}$ detectors), each wavelength band requires a separate detector with appropriate dichroic, focusing optics, support electronics, cooling, and mounting hardware. These requirements for additional components increase the size of an imaging system, resulting in increased power consumption, weight, and cost. Therefore, the broadband approach is being pursued because it offers an advantage of simple, efficient, cost-effective, lightweight, and compact instrument design. Broadband phototransistor arrays proposed to the NASA Earth-Sun Systems Division (ESSD) technology program for the active and passive remote sensing instrument will operate in the spectral range of $0.6-2.5 \mu \mathrm{m}$ and extend this technology to flight missions for next generation. For the broad-spectral active and passive instrument, we will select regions that cover only interest lines (e.g., $\mathrm{CO}_{2}, \mathrm{CH}_{4}$, $\mathrm{H}_{2} \mathrm{O}, \mathrm{CO}$ ) with higher resolution within those bands.

\section{FUTURE DEVELOPMENT OF NEAR-INFRARED DETECTOR FPA}

The record results achieved with discrete $200-\mu \mathrm{m}$ diameter HPTs provide a base for designing and fabrication of arrays of these devices. However, fabrication of the arrays is a challenging task. It requires a very high level of homogeneity of $\mathrm{InGaAsSb} / \mathrm{AlGaAsSb}$ epitaxial layers, including their thickness, doping and chemical composition. For this purpose we are planning to use the Molecular Beam Epitaxy (MBE) - growth method. 
This method provides precisely controlled and reproducible growth of the required multilayer InGaAsSb/AlGaAsSb/GaSb heterostructure on the area of up to $4 \mathrm{~cm}^{2}$. This epitaxial growth was successfully used by the University of Delaware-NASA team for fabrication of the first room temperature HPT with the cutoff wavelength of $2.4 \mu \mathrm{m}$ [15].

There are no reports regarding fabrication of arrays of Sb-based photodetectors with internal gain (APDs or phototransistors), and only few reports about SWIR arrays of InGaAs and HgCdTe APDs. For example; Sensors Unlimited developed 32 x 32 arrays of InGaAs APDs on a $100 \mu \mathrm{m}$ pitch for $1.55 \mu \mathrm{m}$ wavelength [16] and DRS reported about first $\mathrm{HgCdTe}$ APD arrays [17]. NASA LaRC is interested in 2-D arrays fabrication and hybridization in cooperation with the University of Delaware (UD) and a start-up company Advanced Optical Materials, LLC, related to the antimonide based phototransistors.

\section{SUMMARY}

We have demonstrated current single-element infrared detectors and future development of near-infrared focal plane arrays (FPA) for applications to next generation space-based instruments. Most of these activities are based on phototransistor technology, which is offering high internal gain and low NEP operation. Developed phototransistors showed higher responsivity and higher gain with a light collecting area diameter of 200micron. Spectral response measurements and NEP calculations were carried out to the phototransistor to achieve the responsivity at $2.0-\mu \mathrm{m}$ and NEP is several times lower than commercially available state-of-the-art $\mathrm{p}-\mathrm{i}-\mathrm{n}$ photodiodes. On the other hand, phototransistor has achieved two-order-of-magnitude higher responsivity as compare to APDs, despite the higher NEP as compare to Perkin-Elmer APD and lower NEP with respect to SUI/Goodrich APD at near room temperature operation. These new phototransistors will improve the sensitivity of the passive remote sensing instruments and reduce the laser transmitter power for active remote sensing instruments, while eliminating the need for high breakdown voltage avalanche photodiode.

\section{REFERENCES}

1. P. Ambrico, A. Amodeo, P. Girolamo, and N. Spinelli, Applied Optics 39(36), 68476865 (2000).

2. S. Ismail, G. J. Koch, B. W. Barnes, N. Abedin, T. F. Refaat, J. Yu, S. A. Vay, S. A. Kooi, E. V. Browell, U. N. Singh, Proceedings of the $22^{\text {nd }}$ International Laser Radar Conference, 65-68 (2004).

3. T.F. Refaat, M.N. Abedin, O.V. Sulima, S. Ismail, and U.N. Singh, Optical Engineering 43(7), 1647-1650 (2004).

4. T.F. Refaat, M.N. Abedin, O.V. Sulima, U.N. Singh, and S. Ismail, IEDM Tech. Dig., 355-358 (2004).

5. V. Diadiuk, S.H. Groves, C.E. Hurwitz, and G.W. Iseler, IEEE J. Quantum Electronics, QE-17 (2), 260-264 (1981).

6. J.C. Campbell, A.G. Dentai, W.S. Holder and B.L. Kasper, Electron. Lett. 19, 818820 (1983). 
7. K.K. Loi and M. Itzler, Compound Semiconductor 6(3), 1-3 (2000).

8. O.V. Sulima, T.F. Refaat, M.G. Mauk, J.A. Cox, J. Li, S.K. Lohokare, M.N. Abedin, U.N. Singh, and J.A. Rand, Electronics Letters 40, 766-767, (2004).

9. O.V. Sulima, T.F. Refaat, M.G. Mauk, J.A. Cox, J. Li, S.K. Lohokare, M.N. Abedin, U.N. Singh, and J.A. Rand, Presented at 6th Middle-Infrared Optoelectronics Materials and Devices (MIOMD) Conference, in St. Petersburg, Russia, 28 June-1 July 2004.

10. M.N. Abedin, T.F. Refaat, O.V. Sulima, and U.N. Singh, IEEE Trans. Electron Devices 51(12), 2013-2018 (2004).

11. M.N. Abedin, T.F. Refaat, O.V. Sulima, and U.N. Singh, International Journal of High Speed Electronics and Systems, v.15, No.2, pp. 567-582, (2006).

12. T.F. Refaat, M.N. Abedin, O.V. Sulima, S. Ismail, and U.N. Singh, Optical Engineering, v. 43, No. 7, pp.1647-1650 (2004).

13. T.F. Refaat, M.N. Abedin, O.V. Sulima, U.N. Singh and S. Ismail, Technical Digest of the 50th IEEE International Electron Devices Meeting (IEDM), San-Francisco, Ca, December 2004, pp.355 - 358 (2004).

14. T.F. Refaat, M. N. Abedin, O.V. Sulima, S. Ismail and U.N. Singh, Proc. SPIE, v.5887, pp.588706-1 - 588706-13 (2005).

15. O.V. Sulima, K. Swaminathan, T.F. Refaat, N.N. Faleev, A.N. Semenov, V.A. Solov'ev, S.V. Ivanov, M.N. Abedin, U.N. Singh, and D. Prather, Electronics Letters, v.42 (1), pp. 55-56 (2006).

16. J.C. Dries, T. Martin, W. Huang, M.J. Lange, and M. J. Cohen, IEEE LEOS Proceedings, 2002.

17. J.D. Beck, C.-F. Wan, M.A. Kinch, and J.E. Robinson, SPIE v. 4454, pp. 188-197 (2001). 